\section{El Trabajo Cultural}

Miller, Toby (2018). El Trabajo Cultural. Barcelona: Gedisa.

Durante los últimos veinte años, las ciencias sociales han indagado distintas transformaciones de la cultura a escala global, como las llamadas industrias creativas, las nuevas plataformas digitales o su impulso al desarrollo económico y social, aunque en un clima que oscila entre el optimismo y la celebración, dejando zonas grises, poco exploradas o exentas de abordajes críticos. El Trabajo Cultural, donde se reúnen escritos de Miller y otros realizados en colaboración, da un valioso paso en dirección a saldar esta deuda. Lo hace desde una perspectiva que se vale de dos tradiciones críticas del pensamiento en torno a la cultura, como la economía política y los estudios culturales, mediante el análisis de una encomiable diversidad de fuentes y documentos para reconocer un nuevo orden económico global en la producción, distribución y consumo de cultura, cuyo análisis Miller despliega centrándose en la problemática del trabajo en clave global a partir del concepto de la nueva división internacional del trabajo cultural (NITC).

El libro puede dividirse en dos grandes secciones: en la primera, funda su enfoque teórico, lo inscribe en un campo de estudios específico y despliega la construcción de los principales nudos problemáticos que abordará. La segunda, se centra en

DOI 10.5354/0719-1529.2019.55696 los impactos concretos que la NITC tiene sobre sus trabajadores y el medio ambiente, para concluir con la perspectiva de una ecología profunda en torno al trabajo cultural.

El primer capítulo parte de reconocer que la problematización de la cultura actual no puede obviar la dimensión del trabajo, tras haber sido pensada en los últimos años en base a tres actores: compañías, estados y consumidores, dejando fuera a los trabajadores en cuanto partícipes de ese ámbito. $Y$ en ello hay responsabilidad tanto de la economía política, que puso el acento en los procesos globales de concentración de la propiedad a gran escala, como de los estudios culturales, que procuraron centrar su atención en los públicos y audiencias, sea para analizar su empoderamiento o su constitución en productores de sentido. Miller concluye el capítulo reconociendo que si bien el trabajador de la cultura en nuestra era es celebrado como autónomo y libre, debemos estar atentos al rol que comienzan a jugar sus organizaciones en un contexto en el que parece menos evidente que esto se realiza en una correlación positiva entre innovación y flexibilidad laboral.

La apuesta teórica de Miller por una NITC se expone en el segundo capítulo, donde recupera la perspectiva de la dependencia para concebir un nuevo orden global. Sin limitar la definición del trabajo cultural a aquél que produce significaciones, propone comprender también al que da lugar a las herramientas con que éstas son producidas, distribuidas, almacenadas y consumidas, desligándolo así del espacio de excepcionalidad al que suele ser arrojado. En su perspectiva existe una transformación en términos del aprovechamiento que los capitales del norte global hacen de los bajos salarios del sur global, facilitado esto por las tecnologías digitales así como por una asociación entre el trabajo y el placer, que, como plantea Tokumitsu (2015), configura un mandato hegemónico del capitalismo global. Miller, sin embargo, identifica al capital en términos de su pertenencia nacional, lo cual resulta problemático en la medida en que no parte del capital global en su conjunto, cuya manifestación son los capitales individuales, sino que se centra en éstos aún cuando reconoce que hoy el comercio entre empresas supera el comercio entre Estados y que la tercerización de que se valen los integra globalmente. Amén de ello, la NTIC convoca a pensar en la precariedad y en cómo los trabajadores precarios se han venido organizando en los últimos tiempos en el marco de una "nueva fenomenología del trabajo y horizonte de la producción global", cuyas claves

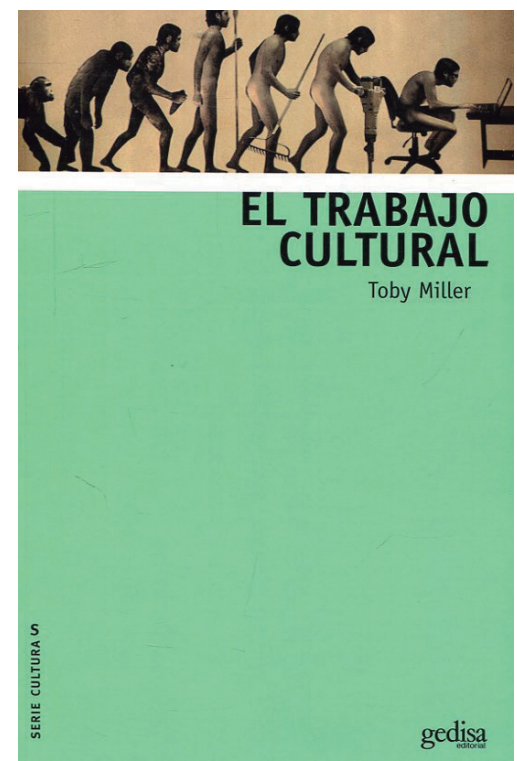


Miller retoma en los capítulos siguientes.

El tercer capitulo resulta ciertamente original en su problematización de la creatividad, que Miller propone hacer recuperando la noción de "hegemonía", planteada en términos de la lógica de acumulación que da sentido a estas construcciones conceptuales. Así entiende al fenómeno del "cibertarianismo", cuyo carácter libertario y determinismo tecnológico pretende un "empoderamiento" de los consumidores y pequeños productores de la cultura, desdeñando la dominación corporativa en el mundo digital global. Para el autor, opera en este sentido una fantasía románticoindividualista de la libertad que no resulta ajena a los propios estudios culturales y que debe ser abordada en términos críticos a partir de comprender el contexto de la NTIC que subyace a la convergencia mediática, uno de los mayores fetiches contemporáneos y menos limpia y novedosa de lo que se pregona.

La segunda parte del libro comienza con un capítulo escrito en coautoría con Bill Graham, donde tratan las fronteras laborales, las minorías migrantes y las diferencias culturales en el marco de la NTIC. Tras considerar el caso de Londres, una de las capitales "creativas" del mundo donde advierten una suerte de subjetividad dividida que desafía al multiculturalismo, en particular respecto de los migrantes provenientes de territorios no imperiales (como los latinos), evidencian la necesidad de un nuevo marco de convivencia que habilite "el bienestar de las minorías, la paz social y la libertad de expresión" más allá de lo meramente discursivo. Luego, Miller se aboca a analizar el modelo de producción de las artes audiovisuales desde la perspectiva de la economía política en el estudio del trabajo cultural, para reconocer el triple pilar de la hegemonía cultural de Hollywood: supresión de derechos laborales, tercerización y explotación de la división global del trabajo y colonialismo lingüístico, en virtud del cual su modelo de explotación, asentado en una "red global de empresas y personas subcontratadas", es actualmente usufructuado por tantas otras industrias.

En siguiente capítulo, escrito con Shin Joung Yeo, se adentra en las condiciones de trabajo de ese modelo de explotación, donde la incertidumbre, el riesgo y la inestabilidad de los negocios son transferidos a sus trabajadores, en un pretendido distanciamiento de la relación salarial capitalista irradiado hacia el conjunto del proceso global de acumulación. Ello es ilustrado a partir de los clústeres de tecnología y artistas construidos en grandes ciudades del norte global, donde las políticas tendientes a consagrarlos en polos creativos en verdad contribuyeron a potenciar dinámicas de precarización laboral, alimentar la especulación inmobiliaria y expulsar a sus habitantes pobres y de clase trabajadora. Aquí radica una de las principales contribuciones de Miller: concebir a los trabajadores del arte y la cultura como parte de un proceso que, bajo la forma de recurso para el desarrollo o conformando clusters creativos, precariza, flexibiliza y empobrece a la clase trabajadora en su conjunto.
El último capítulo se zambulle sobre una de las cuestiones menos problematizadas de la cultura y los medios: su vínculo con el medioambiente. La propuesta de Miller es la ecología profunda; una mirada que, orientada por un materialismo cultural que busca hoy las semillas de los tiempos por venir (Cevasco, 2013), se obliga a atender al proceso completo de "nacimiento, vida y muerte de los medios y sus artefactos y dispositivos de uso" con respecto a generaciones futuras del conjunto de la vida.

El autor recupera en esta propuesta un interés eco-céntrico de carácter intergeneracional aunque ello, entendemos, evidencia un límite vinculado a cierto sustrato idealista y abstracto con que la ecología profunda concibe a la naturaleza ajena a los procesos de acumulación de capital, como condición para poder pensar un vínculo que no se rija por éstos o, peor aún, para imaginar su posibilidad en el marco de la acumulación capitalista que la tiene por objeto y en virtud de la cual el capital se constituye en sujeto del proceso social (Iñigo Carrera, 2003). Más allá de ello, la contribución de Miller radica en el hecho de someter a crítica el supuesto carácter limpio de las tecnologías vinculadas al trabajo cultural y las industrias creativas, a partir de un análisis de su consumo energético, emisiones de carbono, distribución global de basura electrónica así como su impacto sobre la salud, especialmente de los trabajadores del sur global.

Preguntarnos sobre la pretensión del consumo creativo, la po- 
tencialidad de lo digital respecto de nuevos empleos o de una supuesta democracia del consumo para mirar críticamente la conformación de conglomerados globales de medios, su precarización laboral o sus efectos sanitarios y medioambientales desde una propuesta interdisciplinaria, no busca respuestas acabadas, sino que invita a incomodarnos acerca de muchas realidades hegemónicas a partir de las cuales nos definimos y reconocemos. Miller, en síntesis, instiga a preguntarnos acerca de aquello que, como analistas y -finalmente también - trabajadores de la cultura, forma parte de nuestras plataformas y condiciones de existencia y propone un camino de crítica no exento de dificultades, pero potente y provechoso para el campo de los estudios sobre la cultura.

\section{Bibliografía}

Cevasco, M. E. (2013). Diez lecciones sobre estudios culturales. Montevideo: Trilce.

Iñigo Carrera, J. (2013). El capital: razón histórica, sujeto revolucionario y conciencia. Buenos Aires: Imago Mundi.

Tokumitsu, M. (2015). Do what you love. New York: Regan Arts.

\section{Guillermo Quiña}

CONICET y Universidad Nacional del Comahue contact.guillermodgmail.com 